\title{
Primary free fibula reconstruction in life-threatening haemorrhage from high flow arteriovenous malformation of mandible
}

\author{
Parvathi Ravula, Srikanth Rangachari, Rammurti Susarla', Laxman Sambari, \\ Srinivas Saraswathi Jammula \\ Departments of Plastic and Reconstructive Surgery and ${ }^{1}$ Radiology, Nizams Institute of Medical Sciences, Hyderabad, \\ Telangana, India
}

Address for correspondence: Dr. Srinivas Saraswathi Jammula, Flat No 204, Shanthi Soudha Apt, Erramanjil Colony, Panjagutta, Hyderabad - 580 002, Telangana, India. E-mail: ssjammula@gmail.com

\section{ABSTRACT}

Background: High flow arteriovenous malformation (AVM) of the mandible is rare, but it can present as a life-threatening emergency with severe intraoral bleeding for the first time. The gold standard of treatment for an AVM of the mandible is selective embolisation combined with resection and subsequent reconstructions. With the advent of advanced multidisciplinary techniques aimed at definitive therapy, surgical resection and primary reconstruction can provide an ideal anatomical and functional cure. There are no previous reports on primary resection and reconstruction for life-threatening haemorrhage from high flow AVM of the mandible. Aim: We discuss our approach aimed at definitive therapy in life-threatening intraoral bleeding from large high flow AVM of the mandible. Subjects and Methods: Four patients were managed for life-threatening intraoral bleeding during 2015-2017. Compression was applied over the bleeding point before the airway could be secured by endotracheal tube. Under general anaesthesia, the external carotid artery (ECA) was temporarily occluded using an umbilical tape loop ligature to control the bleeding. Emergency selective embolisation was done, followed by curative resection and primary mandible reconstruction using free fibula flap. Outcome assessed. Results: Temporary occlusion of the ECA successfully controlled the bleeding immediately and facilitated selective embolisation and definitive therapy. All the four cases were successfully reconstructed with a good outcome. There was no recurrence during the follow-up period. Conclusion: In life-threatening intraoral bleeding from large high flow AVM of the mandible, emergency selective embolisation followed by curative resection and primary reconstruction is safe in achieving an ideal cure.

\section{KEY WORDS}

High flow arteriovenous malformation mandible; life-threatening intraoral bleeding; primary free fibula reconstruction; temporary external carotid artery occlusion

\begin{tabular}{|l|l|}
\hline \multicolumn{2}{|c|}{ Access this article online } \\
\hline Quick Response Code: & Website: \\
\hline & www.jps.org \\
\cline { 2 - 2 } & DOI: \\
\hline
\end{tabular}

This is an open access journal, and articles are distributed under the terms of the Creative Commons Attribution-NonCommercial-ShareAlike 4.0 License, which allows others to remix, tweak, and build upon the work non-commercially, as long as appropriate credit is given and the new creations are licensed under the identical terms.

For reprints contact: reprints@medknow.com

How to cite this article: Ravula P, Rangachari S, Susarla R, Sambari L, Jammula SS. Primary free fibula reconstruction in lifethreatening haemorrhage from high flow arteriovenous malformation of mandible. Indian J Plast Surg 2018;51:222-30. 


\section{INTRODUCTION}

anagement of life threatening intra oral bleeding from a large high flow AVM of the Mandible is a challenging task. It may present for the first time and may even lead to death. The key factor in the management of these patients is securing the airway and temporary control of bleeding to facilitate the definitive treatment.

Although various methods of treatments have been reported in the literature, the gold standard is selective embolization combined with resection and reconstruction for a definitive cure. We report on our protocol for the management of AVM of mandible presenting with life threatening bleeding.

\section{SUBJECTS AND METHODS}

Four patients were treated for life-threatening intraoral bleeding from arteriovenous malformation (AVM) mandible during the period 2015-2017 who underwent selective embolisation, curative resection and primary free fibula reconstruction.

All the four patients presented in an unstable condition, with uncontrolled intraoral bleeding. An intravenous line was secured, and the patients were urgently shifted to the operation theatre for airway access and control of bleeding. Under general anaesthesia, local measures like transfixation sutures at the bleeding site were attempted but to no avail. The ipsilateral external carotid artery (ECA) was exposed and snared with a loop of umbilical tape to control the bleeding [Figure 1]. One patient needed an additional interdental wire fixation over a piece of Gelfoam; patients were stabilised and underwent emergency angiogram and selective embolisation within the next $24 \mathrm{~h}$ [Figure 2]. Subsequently, patients were further stabilised haemodynamically.

The diagnostic protocol included angiogram, computed tomography (CT) [Figure 3] scan and magnetic resonance imaging (in two patients who had lower lip and chin involvement).

Surgical intervention was done within 3-7 days post-embolisation. All the patients had an elective tracheostomy to facilitate a safe airway. Curative resection of the involved mandible and reconstruction

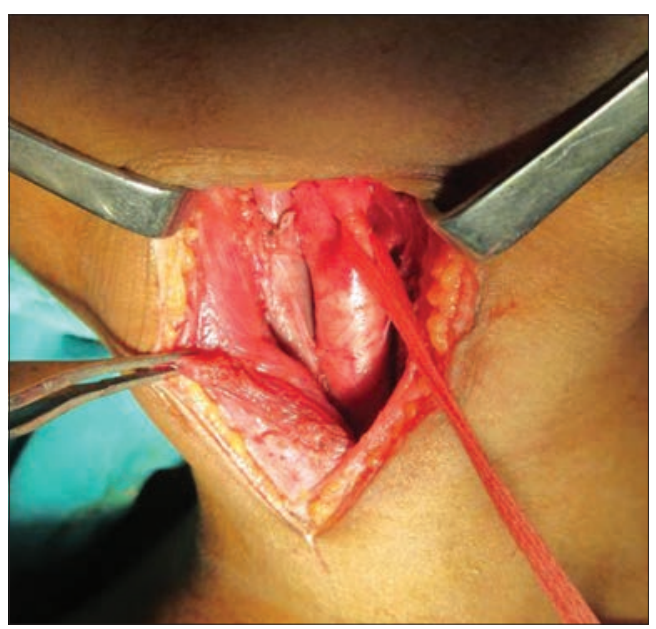

Figure 1: Temporary external carotid artery control using loop ligature just distal to superior thyroid branch helps in controlling the bleeding

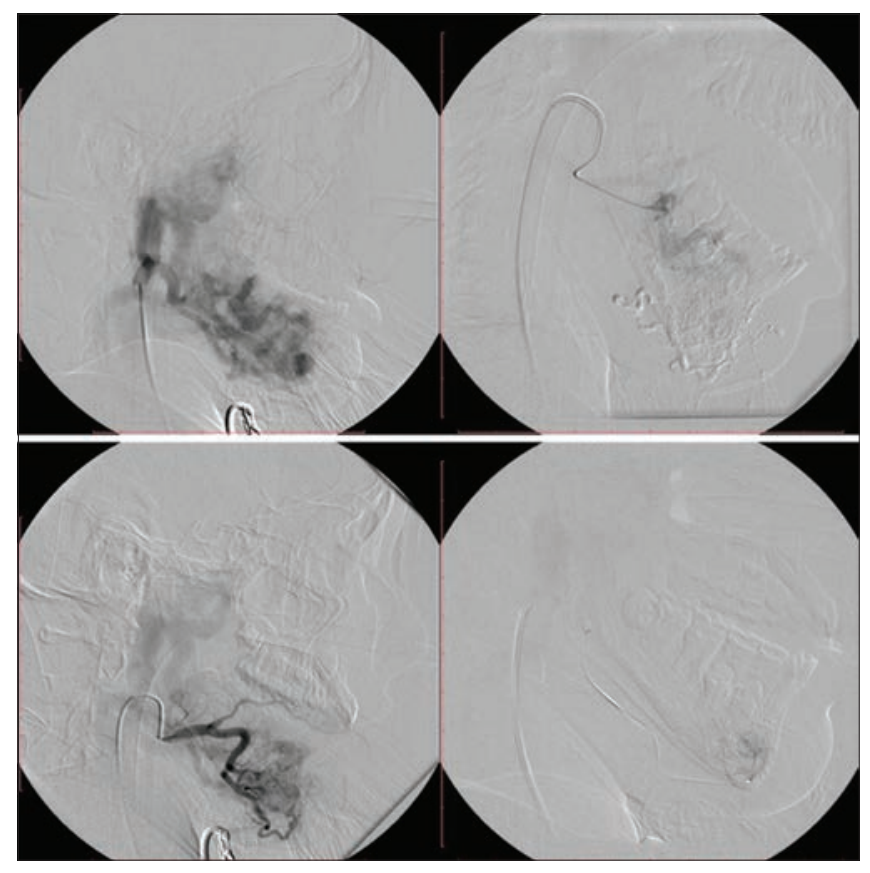

Figure 2: Selective embolisation of facial and lingual branches pre- and post-embolisation using N-butyl cyanoacrylate - Pre- and post-embolisation

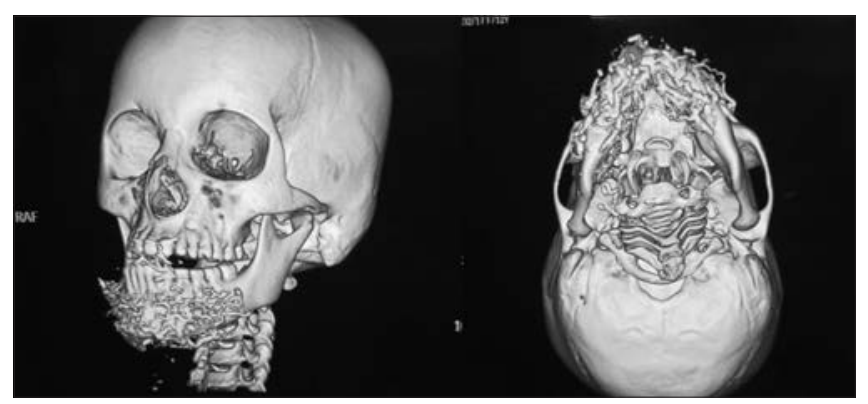

Figure 3: Pre-operative computed tomography angiogram showing bilateral involvement of the Mandible

of the defect with primary free osteocutaneous fibula flap was performed. The loop ligatures on the external Indian Journal of Plastic Surgery Volume 51 Issue 2 May-August 2018 
carotid were removed only after the excision of the lesion in the mandible. All the patients were discharged after the closure of the tracheostomy.

\section{RESULTS}

Totally four patients were managed for the intraoral bleeding from AVM mandible.

Age group ranged from 12 to 23 years, there were three females and one male patient.

All the patients had a previous history of minor intraoral bleeding varying from 3 to 9 episodes. Two of them were previously diagnosed and received 2-3 embolisations, alarming bleeding started while they were waiting in the hospital for the scheduled embolisation procedure. Other two patients were undiagnosed and presented directly with severe intraoral bleeding in an unstable condition.

Arteriograms showed feeders arising from the facial, lingual, internal maxillary vessels and from both sides in two patients. All the embolisation procedures were performed using N-butyl cyanoacrylate through the femoral route; two of the four patients had bilateral selective embolisations. One patient started bleeding while waiting for surgical intervention and second embolisation was needed. During resuscitation, period 6-8 transfusions were needed.

The final decision for resection was made by the interventional radiologist and the plastic surgeon based on the patient presentation, investigative findings and the completeness of the embolisation. Moderate bleeding occurred intraoperatively, but none of the patients received any intra-operative- or post-operative blood transfusions.

The lesion was limited to the mandible in two patients; in the other two patients, more than $80 \%$ of the lip and chin along with submental and submandibular tissues was involved [Figure 4].

Mandible defects extended from one angle to the contra-lateral parasymphyseal region and beyond [Figure 5]. Primary reconstruction was performed with free osteocutaneous fibula flap [Figure 6]. Facial artery and superior thyroid arteries were used as recipient vessels, each in two patients [Table 1]. In one of

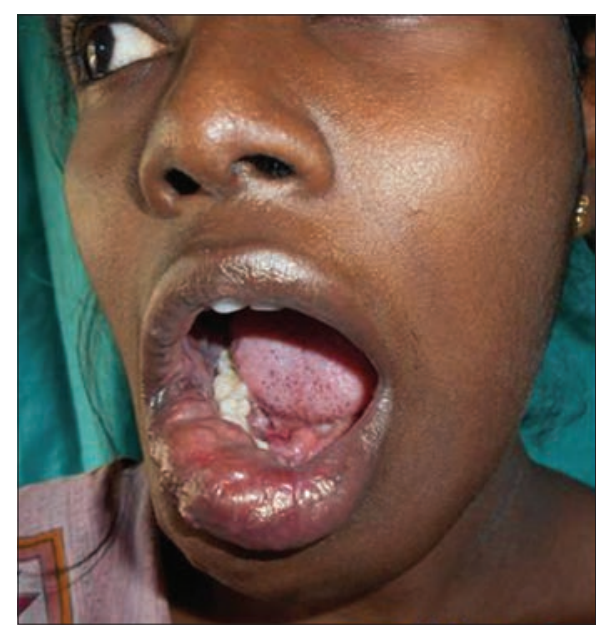

Figure 4: Arteriovenous malformation mandible involving $80 \%$ of the lip and chin

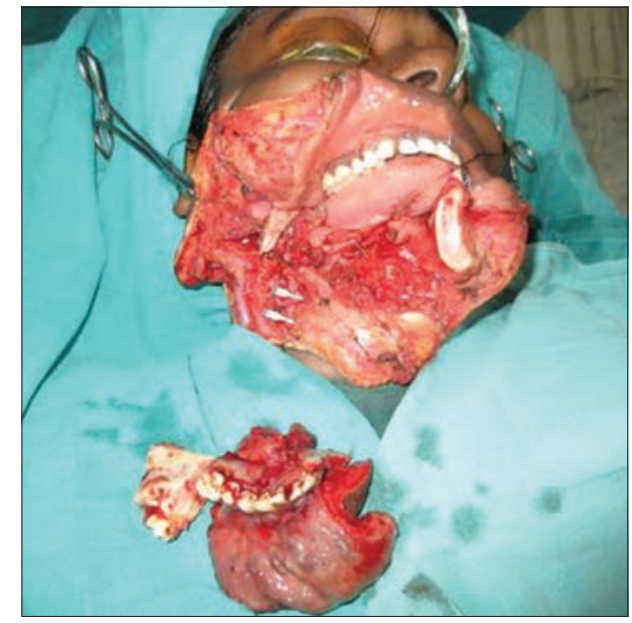

Figure 5: Mandible defects extended from one angle to contra-lateral parasymphyseal region and beyond in other cases

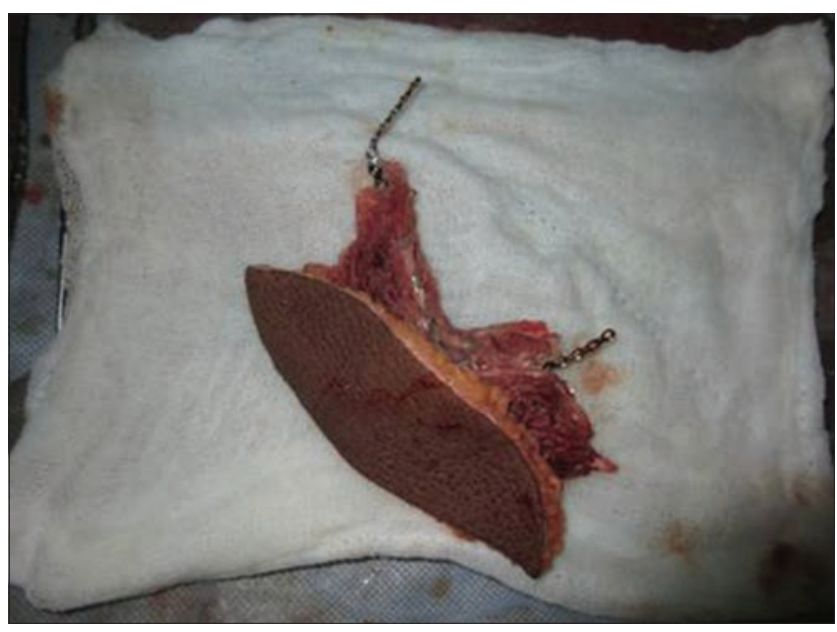

Figure 6: Fabricated free osteocutaneous fibula flap

these patients, glue material was seen in the ipsilateral facial vessels, hence contra-lateral superior thyroid artery was used as the recipient vessel. 
The single osteotomy was done in three cases, one patient needed two osteotomies. All the skeletal fixations were done using titanium mini plates.

External jugular vein, facial accompanying veins or a tributary of internal jugular veins were used for venous anastomosis.

Skin paddle was used as mucosa in two patients, and in the other two cases, skin paddle was used to reconstruct the mucosa and $80 \%$ of the lower lip and chin [Figure 7].

There were no re explorations or flap failures either complete or partial. All the patients were discharged between the $14^{\text {th }}$ and $17^{\text {th }}$ day following the surgery. Patients were followed up regularly, for a minimum period of 6 months to more than 2 years [Figure 8].

One patient needed palmaris longus graft for restoration of continence for more than $80 \%$ lower lip loss and chin. Two patients needed skin paddle adjustments. One patient had shown plate breakage at the angle region with the anterior displacement of the ramus, at 2 years

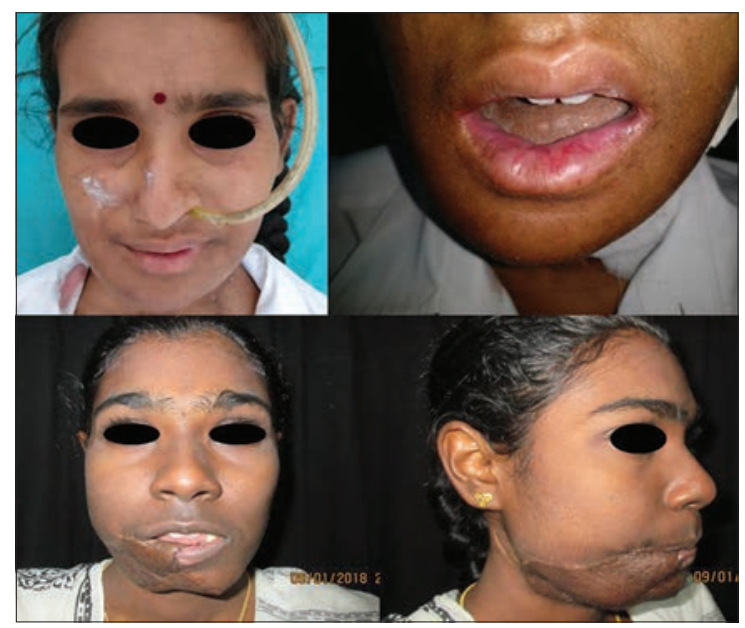

Figure 7: Skin paddle was used as mucosa in two patients, and skin and mucosa in other two cases follow-up, but functionally patient did not complain any problem. The CT scan did not show any evidence of recurrence, patient underwent refixation of the segments. All the four patients were satisfied with the outcome [Figures 9-12].

Patients were further counselled for dental rehabilitation.

\section{DISCUSSION}

AVM arising from the mandible are very rare. It can present with potentially life-threatening intraoral bleeding for the first time that may even lead to death because of severe exsanguination..$^{[1-6]}$

Intraosseous vascular malformations are rare (1\%), about half of them occur in the skull and maxillofacial region. More commonly seen in the mandible than in the maxilla, with a female predominance. ${ }^{[7,8]}$

They occur due to errors during the embryogenesis, and may not be visible even though they are present at the time of birth. Most of the patients are children

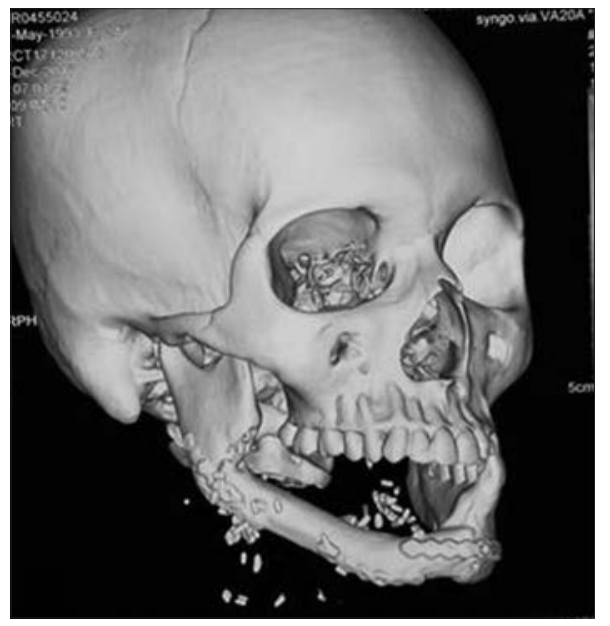

Figure 8: Follow up computed tomography scan following resection and primary reconstruction of mandible with osteocutaneous free fibula flap

Table 1: Clinical details of the patients

\begin{tabular}{|c|c|c|c|c|c|}
\hline Age/Sex & $\begin{array}{l}\text { Previous H/O Minor } \\
\text { Intra Oral Bleeding }\end{array}$ & $\begin{array}{l}\text { H/O Previous } \\
\text { Embolisations }\end{array}$ & $\begin{array}{l}\text { Time of surgery } \\
\text { post embolisation }\end{array}$ & $\begin{array}{l}\text { Extent of the Mandible } \\
\text { Resection }\end{array}$ & Recipient vessels \\
\hline $16 / M$ & 3 episodes & 2 episodes & 7 days & $\begin{array}{l}\text { Right angle to left first molar } \\
\text { teeth }\end{array}$ & Left facial A, CFV and EJV \\
\hline $20 / F$ & 5 episodes & No & 3 days & Left angle to right first molar & $\begin{array}{l}\text { Right superior thyroid, CFV, } \\
\text { EJV }\end{array}$ \\
\hline $23 / F$ & 4 episodes & 3 episodes & 2 days & $\begin{array}{l}\text { Right subcondylar to left } \\
\text { canine }\end{array}$ & $\begin{array}{l}\text { Right superior thyroid } A \text {, } \\
\text { middle thyroid } \mathrm{V} \text { and } \mathrm{EJV}\end{array}$ \\
\hline $12 / \mathrm{F}$ & 9 episodes & No & 5 days & Right ramus to left angle & $\begin{array}{l}\text { Left facial } A \text {, facial } V \text { and } \\
\text { EJV }\end{array}$ \\
\hline
\end{tabular}




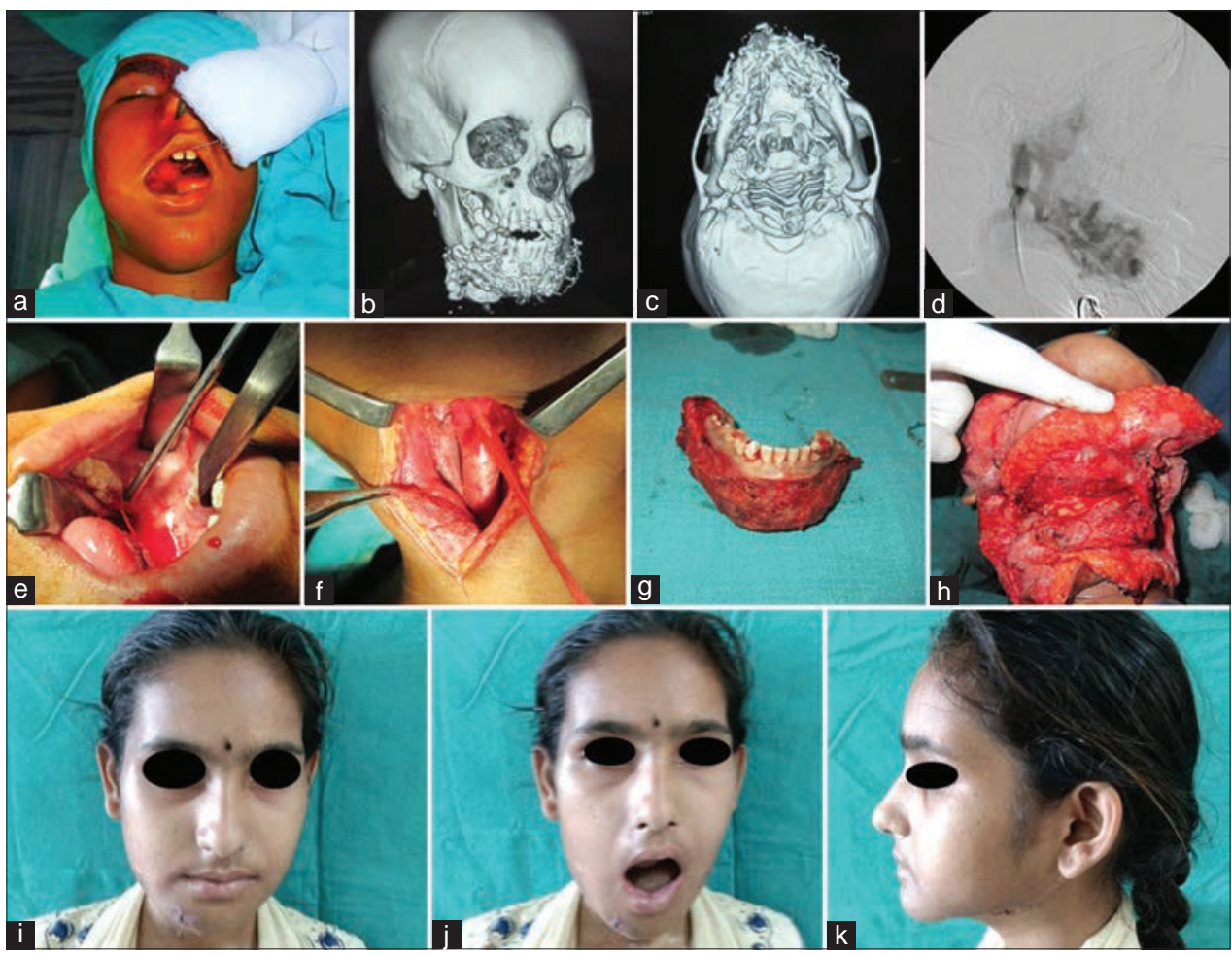

Figure 9: Case 1: (a) - Pre -operativeOp 12 yearrss child with bleeding, (b and c) - computed tomography CT Angiogram, (d) - Angiogram, (e) - Bleeding from the tooth (f) - external carotid arteryECA control, (g) - resected segment (h) - Post-resection defect, (i-k) - 6 months follow up

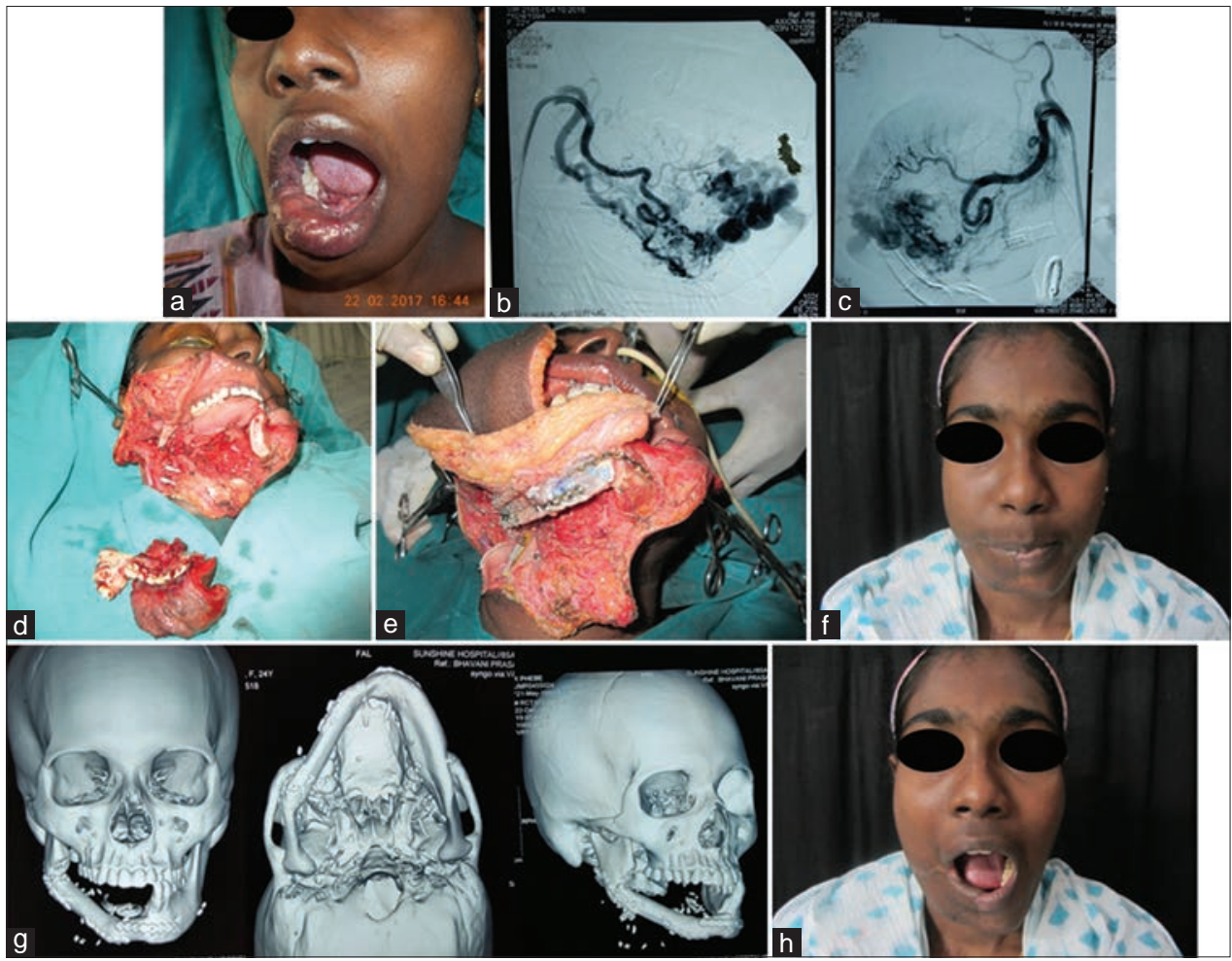

Figure 10: Case 2: (a) - Pre-operative, (b and c)- angiogram, (d and e) - Surgical resection and reconstruction, (f and $h$ ) - Follow up 16 months, (g) - Post -operativeOP computed tomographyCT scan

or adolescents..$^{[6,9-13]}$ Puberty and pregnancy-induced hormonal changes influence and trigger the rapid growth. ${ }^{[9]}$ Indian Journal of Plastic Surgery Volume 51 Issue 2 May-August 2018
Clinical presentations may include slow-growing expansile mass, repeated minor bleeding from the 
gingiva due to trivial trauma, such as brushing, loosening of teeth, numbness over the lower lip area, deformity of the lower jaw and malocclusion. Severe bleeding during tooth extraction or biopsy of the swelling can cause haemorrhagic shock and death. ${ }^{[12-17]}$

Radiologically, it may appear as a radiolucent lesion or erosion of the alveolus with apparently floating teeth. CT

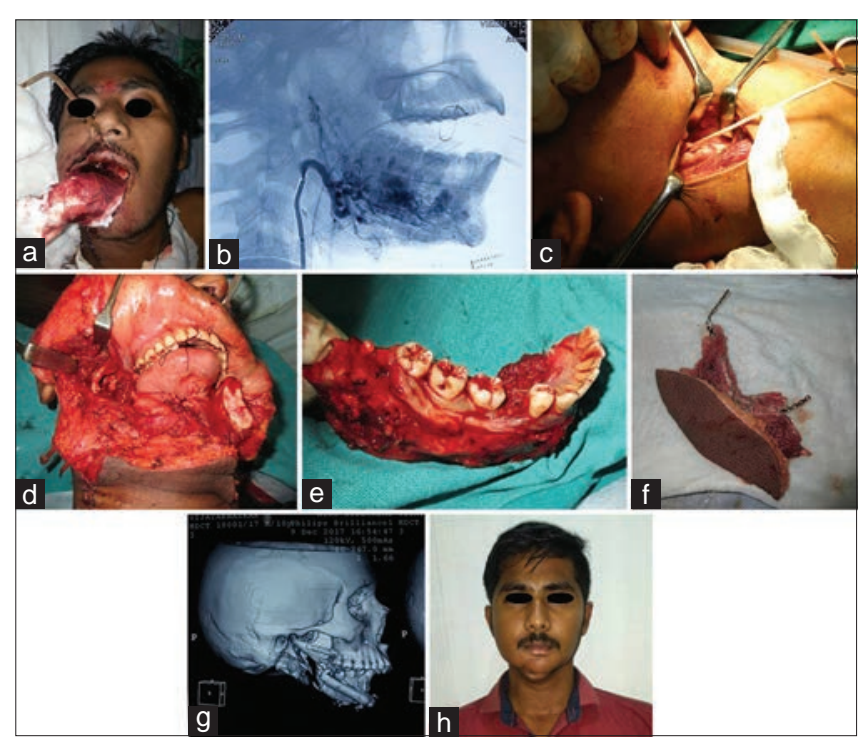

Figure 11: Case 3: (a) - Pre -operative,

(b) - angiogram, (c) - external carotid arteryECA control, (d-f) surgical resection and reconstruction, $(\mathrm{g})$ - 18 months follow up, (h) -refixation of broken plate and and 24 months follow up scans or MR imaging helps in knowing the extent of the lesion, but angiogram is essential to know the feeding arteries, draining veins, the flow rate and the collateral flow of the lesion, which are crucial for treatment. lanning. ${ }^{[12]}$ The treatment strategy, risk of recurrence and the potential for serious morbidity will all depend on the haemodynamics of the lesion.

The lower pressures within the central vascular channels (Nidus) of the malformation are the main driving forces for the surrounding feeding vessels. If the flow in any of the proximal feeding vessels is obliterated without obliterating the nidus, the haemodynamics in the vascular channels is compensated by immediate enlargement of the remaining feeding vessels. This can happen by the recruitment of surrounding non-existing feeders from other branches of ECA, vertebrobasilar system or the internal carotid system either from the same side or contra-lateral side or from both sides. ${ }^{[18]}$

Management of the high-flow AVM mandible has been complex, especially when the patient presents as an emergency with severe intraoral bleeding, and the associated morbidity and mortality are significantly high.

The rarity of the lesion may limit the surgeon's exposure, and experience with its management and the multidisciplinary
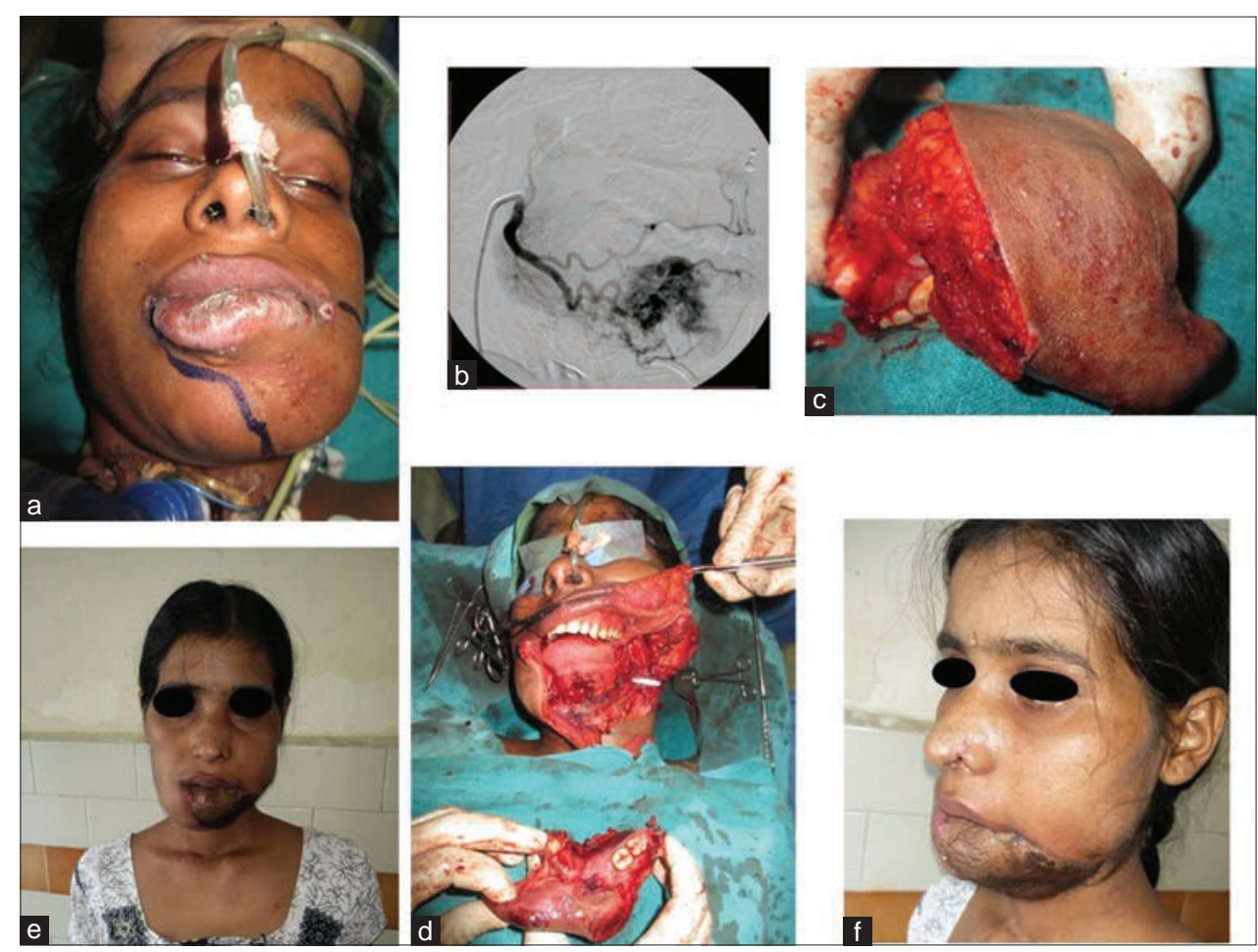

Figure 12: Case 4: (a) - pre-operative, (b) - Angiogram, (c and d) - Surgical resection, (e and f) - 28 months follow up 
team approach is essential for an ideal cure. The basic aim of the treatment of AVM is to identify and remove the nidus completely and thus avoid the recurrence.

Many nonsurgical and surgical treatment options have been proposed in the literature. Embolisation using various materials is an established non-surgical method to obliterate the AVM, though injection of sclerosing agents and radiotherapy ${ }^{[19-21]}$ have been described. Ligation of external carotid artery has been described, presently it is not practiced and not advisable as it promotes the rapid appearance of a collateral circulation, and future embolization would be impossible. ${ }^{[22,23]}$

Various other embolisation techniques like approaching the lesion from both the arterial and venous side, transosseous embolisations either through a direct puncture or transcutaneous transosseous needle, buccal bur holes or through extraction sockets ${ }^{[24-26]}$ have been reported as a definitive procedure or as an adjunct to surgical intervention.

Cyanoacrylate is the most commonly used material. Various reports mention that selective embolisation using cyanoacrylate has been successful in obliterating the lesion and bone regeneration without recurrence. ${ }^{[27]}$ However, there have been reports on associated complications such as tissue inflammation, infection, recurrent bleeding, late complications like osteomyelitis, osteonecrosis that may need surgical intervention. ${ }^{[28]}$

Larger lesions need repeated embolisations to obliterate as many feeders as possible and surgical intervention either to completely eradicate the residual lesion or reconstruction in massive lesions. ${ }^{[28]}$

Whenever a large bleeding high flow intraosseous AVM is considered for treatment, one must plan for an ideal cure. The gold standard for the treatment is super selective embolisation of the nidus and the surgical resection. The standard approach includes accurate diagnosis, selective embolisation and surgical resection of the lesion soon after the embolisation (Larsen and Peterson 1993) preferably within $24-48$ h to $7-14$ days after the last embolisation to avoid development of collateral circulation.

The choice of surgical intervention depends on the size and location of the lesion in the mandible and the age of the patient. Various surgical interventions described in the literature include curettage through different approaches, extracorporeal curettage, and replantation, resection and reconstruction either with autologous bone graft (vascularised or nonvascularised) or alloplastic reconstruction plate.

Yoshiga reported an asymptomatic AVM mandible managed by repeated embolisations as long as 7 years that were not amenable for any further embolisations and needed surgical resection and replantation. ${ }^{[14]}$

Behnia et al. felt embolisations alone may not be the universal treatment option, and surgical treatment may be needed. Their approach of trans mandibular curettage by proximal osteotomy for small lesions, and the resection and immediate replantation for large lesions avoided the need for bone graft while preserving the form and function. ${ }^{[29]}$ Whereas Oka et al. used the resected part of the involved mandible as a crib to carry the cancellous bone graft from the iliac crest and replanted it using a reconstruction plate.

A comprehensive study (Chen) on the effectiveness of various treatment modalities like radiotherapy, injection sclerotherapy, bone wax packing and curettage, resection of the bone etc., for oral and maxillofacial AVMs concluded that none of the lesions were cured by embolisation alone and for the intraosseous AVMs surgical resection is an effective method of the treatment for complete cure. ${ }^{[30]}$

There have been recent reports on surgical resection and microvascular reconstruction of the AVM mandible following multiple embolisation procedures. These reconstructions were performed in a stable patient as a delayed elective procedure.

Bagherzadegan et al. reported partial resection of AVM mandible and primary vascularised Ileac crest graft 1 month after the last stabilisation procedure for severe recurrent bleeding following several embolisations. ${ }^{[31]}$

Sakkas et al. reported a secondary reconstruction with a free fibular flap for a spontaneous fracture of the mandible after 1 year that was managed by multiple embolisations including intraosseous embolisation. ${ }^{[12]}$

Kaderbhai et al., reported segmental resection and reconstruction using a vascularised deep circumflex iliac artery bone flap in two children ( 5 and 14 years) 
for recurrent life threatening bleeding after repeated embolisations which were not amenable for further embolisations. However, at 3 years follow-up one of the children had resorption of most of the bone, and a subsequent fibula free flap was successfully undertaken. ${ }^{[32]}$

Thus the reports suggest that repeated embolisations may have logistic problems for individual patients and may not be able to provide the definitive therapy. Reports mention that patients who were embolised and planned for elective surgical intervention may not agree for resection, and some may not come back for the surgery and finally present with life-threatening bleeding due to massive recurrence.

We feel that large high flow AVM mandible presenting with life-threatening bleeding may be considered for primary definitive therapy once the bleeding is controlled by emergency embolisation and the patient is stabilised, thus avoiding any further complications.

In the present study, we would like to propose that our protocol for controlling the bleeding facilitates emergency selective embolisation which allows aiming at definitive therapy.

First and foremost priority in life-threatening intraoral bleeding from AVM is to secure the airway, followed by temporary control of the bleeding. Achieving a temporary loop ligature to control over the ipsilateral ECA with an umbilical tape is an effective alternative approach to the ligation of ECA. This will immediately control the bleeding and the patient can be considered for emergency embolisation.

Even a single selective embolisation procedure can effectively obliterate significant flow of the lesion, and the bleeding is controlled most of the times. This allows the further stabilisation and prepares the patient for definitive surgery.

In this series, primary curative resection and reconstruction were decided by the conclusive discussion amongst the interventional radiologist and plastic surgeon based on the extent of the lesion, flow dynamics and the risk of recurrent bleeding.

Primary free fibula reconstruction is an established procedure for mandibular reconstruction from both aesthetic and functional point. Primary reconstruction has its own advantages over the more complex secondary reconstruction due to previous surgical scarring and accessibility to the reliable recipient vessels, even though the complication rates were surprisingly similar. ${ }^{[33]}$

As most of the patients are young and immediately stabilises with resuscitation and selective embolisation, we feel curative resection and primary free fibula reconstruction of large AVM mandible presenting with life-threatening bleeding would be an ideal option for good aesthetic and functional outcome while avoiding further complications.

\section{CONCLUSION}

The advent of endovascular techniques has enabled multi-modal treatment options for the management of AVMs. The key factor in the management of life-threatening intraoral bleeding from large AVM mandible is securing the airway and immediate selective embolisation. This further facilitates to aim at a definitive cure. Complete resection of the lesion and primary reconstruction with free osteocutaneous fibula flap is safe and provides an ideal option for anatomical reconstruction and future dental rehabilitation.

\section{Declaration of patient consent}

The authors certify that they have obtained all appropriate patient consent forms. In the form, the patient has given their consent for their images and other clinical information to be reported in the journal. The patient understand that names and initials will not be published and due efforts will be made to conceal identity, but anonymity cannot be guaranteed.

\section{Financial support and sponsorship \\ Nil.}

\section{Conflicts of interest}

There are no conflicts of interest.

\section{REFERENCES}

1. Lamberg MA, Tasanen A, Jääskeläinen J. Fatality from central hemangioma of the mandible. J Oral Surg 1979;37:578-84.

2. Anderson JH, Grisius RJ, McKean TW. Arteriovenous malformation of the mandible. Oral Surg Oral Med Oral Pathol 1981;52:118-25.

3. Mosnier I, Derhy S, Martin F, Princ G. Arteriovenous malformation of the mandible. Apropos of a case in a 6-year-old child. Ann

Indian Journal of Plastic Surgery Volume 51 Issue 2 May-August 2018 
Otolaryngol Chir Cervicofac 1996;113:434-9.

4. Jackson IT, Jack CR, Aycock B, Dubin B, Irons GB. The management of intraosseous arteriovenous malformations in the head and neck area. Plast Reconstr Surg 1989;84:47-54.

5. Holt GR, Tinsley PP Jr., Aufdemorte TB, Steed DL, Dittman WI. Arteriovenous malformation of the mandible. Otolaryngol Head Neck Surg 1983;91:573-8.

6. Engel JD, Supancic JS, Davis LF. Arteriovenous malformation of the mandible: Life-threatening complications during tooth extraction. J Am Dent Assoc 1995;126:237-42.

7. Persky MS. Congenital vascular lesions of the head and neck. Laryngoscope 1986;96:1002-15.

8. Unni KK, Ivins JC, Beabout JW, Dahlin DC. Hemangioma, hemangiopericytoma, and hemangioendothelioma (angiosarcoma) of bone. Cancer 1971;27:1403-14.

9. Lasjaunias $P$, ter Brugge KG, Berenstein A. Surgical neuroangiography clinical and interventional aspects in children. $2^{\text {nd }}$ ed. Berlin: Springer; 2006.

10. Wang C, Yan Q, Xie X, Li J, Zhou D. Embolization of a bleeding maxillary arteriovenous malformation via the superficial temporal artery after external carotid artery ligation. Korean J Radiol. 2008; 9: 182-185.

11. Sasaki R, Okamoto T, Komiya $\mathrm{C}$, Uchiyama H, Ando T, Ogiuchi $\mathrm{H}$. Mandibular gingival arteriovenous malformation in pregnancy. $\mathrm{Br}$ J Oral Maxillofac Surg 2008;46:675-6.

12. Sakkas N, Schramm A, Metzger MC, Berlis A, Schmelzeisen R, Otten JE, et al. Arteriovenous malformation of the mandible: A life-threatening situation. Ann Hematol 2007;86:409-13.

13. Benndorf G, Campi A, Hell B, Hölzle F, Lund J, Bier J, et al. Endovascular management of a bleeding mandibular arteriovenous malformation by transfemoral venous embolization with NBCA. AJNR Am J Neuroradiol 2001;22:359-62.

14. Yoshiga K, Tanimoto K, Okui T, Kobayashi M. High-flow arteriovenous malformation of the mandible: Treatment and 7-year follow-up. Br J Oral Maxillofac Surg 2003;41:348-50.

15. Giaoui L, Princ G, Chiras J, Guilbert F, Bertrand JC. Treatment of vascular malformations of the mandible: A description of 12 cases. Int J Oral Maxillofac Surg 2003;32:132-6.

16. Hohlweg-Majert B, Metzger MC, Schramm A, Berlis A, Schön R. Complication of intraoral procedures in patients with vascular tumors. J Craniofac Surg 2008;19:816-9.

17. Shum JW, Clayman L. Resection and immediate reconstruction of a pediatric vascular malformation in the mandible: Case report. Oral Surg Oral Med Oral Pathol Oral Radiol Endod 2010;109:517-24.

18. Larsen PE, Peterson LJ. A systematic approach to management of high-flow vascular malformations of the mandible. $\mathrm{J}$ Oral Maxillofac Surg 1993;51:62-9.

19. Lindemann A, Lorenz 0 : The tumors of the oral cavity, the jaw and the face. Stuttgart, Scientific Publishing Company MB, 1950, p 81.

20. Akita S, Akino K, Tanaka K, Anraku K, Yano H, Hirano A. (2006) Therapeutic choice for craniofacial venous malformations. J Craniofac Surg 17(4):729-35.

21. Siu WW, Weill A, Gariepy JL, Moret J, Marotta T. (2006) Arteriovenous malformation of the mandible: Embolization and direct injection therapy. J Vasc Interv Radiol 12(9):1095-98.

22. Noreau G, Landry PP, Morais D. Arteriovenous malformation of the mandible: Review of literature and case history. J Can Dent Assoc 2001;67:646-51.

23. Siu WW, Weill A, Gariepy JL, Moret J, Marotta T. Arteriovenous malformation of the mandible: Embolization and direct injection therapy. J Vasc Interv Radiol 2006;12:1095-8.

24. Kademani D, Costello BJ, Ditty D, Quinn P. An alternative approach to maxillofacial arteriovenous malformations with transosseous direct puncture embolization. Oral Surg Oral Med Oral Pathol Oral Radiol Endod 2004;97:701-6.

25. Brusati R, Galioto S, Biglioli F, Goisis M. Conservative treatment of arteriovenous malformations of the mandible. Int $\mathrm{J}$ Oral Maxillofac Surg 2001;30:397-401.

26. Fan X, Zhang Z, Zhang C, Tang Y, Hu Y, Mao Q, et al. Direct-puncture embolization of intraosseous arteriovenous malformation of jaws. J Oral Maxillofac Surg 2002;60:890-6.

27. Chhoeurn V, de Villa GH, Lo LJ. Osseous regeneration after embolization of mandibular arteriovenous malformation. Chang Gung Med J 2003;26:937-42.

28. Churojana A, Khumtong R, Songsaeng D, Chongkolwatana C, Suthipongchai $\mathrm{S}$. Life-threatening arteriovenous malformation of the maxillomandibular region and treatment outcomes. Interv Neuroradiol 2012;18:49-59.

29. Behnia $\mathrm{H}$, Motamedi $\mathrm{MH}$. Treatment of central arteriovenous malformation of the mandible via resection and immediate replantation of the segment. J Oral Maxillofac Surg 1997;55:79-84.

30. Chen WD, Wang J, Li J, Xu L. Comprehensive Treatment of Arteriovenous Malformations in the Oral and Maxillofacial Region. J Oral Maxillofac Surg 2005;63:1484-8.

31. Bagherzadegan $N$, Hohlweg-Majert $B$, Mücke $T$, Haerle $S$, Deppe $\mathrm{H}$, Wolff KD, et al. Microvascular bone grafting: A new long-term solution for intraosseous arteriovenous malformations of the mandible in children. Journal of Cranio-Maxillo-Facial Surgery 2011;39:431-4.

32. Kaderbhai J, Breik $O$, Heggie AA, Penington AJ. High-flow paediatric mandibular arteriovenous malformations: Case reports and a review of current management. Int J Oral Maxillofac. Surg. Dec 2017;46:1650-5.

33. Andrade W, Grover H, Lipa JE, Bang C, Gilbert R, Neligan PC. Reconstructive options and outcomes in primary vs. Secondary mandibular reconstruction. J Reconstr Microsurg 2006;22:A008. 